\title{
MICHEL FOUCAULT E A CONSTRUÇÃO DISCURSIVA DO CORPO DO SUJEITO MODERNO E SUA RELAÇÃO COM A PSICOLOGIA ${ }^{1}$
}

\author{
Fernando de Almeida Silveira
}

\begin{abstract}
RESUMO. Michel Foucault investiga "a história das relações que o pensamento mantém com a verdade" e como se estabelece a correlação entre pensamento e verdade, tendo o enunciado do corpo como elemento discursivo fundamental na constituição dos jogos de verdades sobre o sujeito moderno. Através da leitura da bibliografia desse autor, de comentaristas e de outros filósofos modernos, esta pesquisa estuda a questão do corpo na fase arqueológica foucaultiana, principalmente no livro As Palavras e As Coisas, destacando as formações discursivas do corpo, da vida e do homem em seus efeitos subjetivadores, com especial referência à constituição discursiva do sujeito psicológico. Verificou-se que Foucault desnaturaliza o corpo, apresentando-o como conceito-chave (ou grade de especificação) na produção de discursos sobre o homem moderno, o que nos permite também compreender a psiqué não como emanação ou essência metafísica do corpo, mas como instrumento discursivo, singularmente emergente na história do pensamento moderno.
\end{abstract}

Palavras-chave: Foucault, corpo, discurso.

\section{MICHEL FOUCAULT AND THE DISCURSIVE CONSTRUCTION OF MODERN SUBJECT'S BODY AND THEIR RELATION WITH PSYCHOLOGY}

\begin{abstract}
Michel Foucault investigates "the history of the relations between thought and truth" and how the correlation between the two factors is established. The body's enunciation is a fundamental discursive element on the modern subject's truth game. Foucault's bibliography, commentators and other modern philosophers foreground current research which studies the issue of the body in the French philosopher's archaeological phase, mainly in The Order of Things. The discursive constitution of the body, life and man in their subjectification effects are highlighted, with special reference to the psychological subject's discursive constitution. In fact, Foucault de-naturalizes the body and presents it as a key concept (specification grade) in the production of discourses on modern man. Psyche is thus understood not as emanation or as the body's metaphysical essence, but as a discursive instrument, singularly emergent in the history of modern thought (FAPESP).
\end{abstract}

Key words: Foucault, body, discourse.

\section{MICHEL FOUCAULT Y LA CONSTRUCCIÓN DISCURSIVA DEL CUERPO DE LO SUJETO MODERNO Y SU RELACIÓN CON LA PSICOLOGIA}

\begin{abstract}
RESUMEN. Michel Foucault investiga "la historia de las relaciones que el pensamiento mantiene con la verdad" y como la correlación entre el pensamiento y la verdad es establecida, al traer el cuerpo como elemento discursivo fundamental en los juegos de verdades sobre la constitución del sujeto moderno. A través de la lectura de la bibliografía de este autor, comentaristas y otros filósofos, la investigación estudia la cuestión del cuerpo en la fase de Foucault arqueológica, principalmente en "Las Palabras y las Cosas", destacando las formaciones discursivas del cuerpo, de la vida y del hombre en sus efectos sujetivadores, a la constitución del sujeto psicológico. Se comprobó que Foucault desnaturaliza el cuerpo, presentándolo como concepto-clave en la producción de discursos sobre el hombre moderno. Lo que nos permite comprender también la psiqué, no como emanación o esencia metafísica del cuerpo, sino como instrumento discursivo, emergente en la historia del pensamiento moderno.
\end{abstract}

Palabras-clave: Foucault, cuerpo, discurso.

\section{Apoio: Fapesp.}

* Doutor em Psicologia na área de Fundamentos Históricos e Epistemológicos da Psicologia. Professor Adjunto de Psicologia e Humanismo e de Ética da Universidade Federal de São Paulo-Campus Baixada Santista. 
Desde o seu primeiro grande livro, publicado em 1961, até os seus últimos livros, publicados em 1984, Michel Foucault (1926/1984), em sua obra, não só privilegiou de maneira singular a questão do corpo, mas também colaborou para um rearranjo renovador dos estudos epistemológicos da filosofia francesa sobre esta temática.

A divisão de sua obra em três fases distintas nos leva a reconhecer que desde a década de 1960, com a publicação de A história da loucura (1961), O nascimento da clínica (1963), As Palavras e As Coisas (1966) e A Arqueologia do saber (1969), temos, primeiramente, um Foucault voltado para a articulação das relações entre os meios discursivos e não discursivos na constituição dos saberes, seja, por exemplo, no que se refere à enunciação do sujeito louco, seja do indivíduo na clínica médica.

Em As Palavras e As Coisas (Foucault, 1966), suas investigações sobre a racionalidade dos saberes modernos na sociedade ocidental foram voltadas para o estudo preponderante dos saberes científicos em geral, e mais especificamente, sobre a questão do surgimento do homem enquanto nova figura de conhecimento a partir do advento da Modernidade, apropriada de maneira focal pelas denominadas ciências humanas, na ânsia de seus pesquisadores pela consolidação de seus respectivos objetos de pesquisa, seja na Sociologia, seja na Antropologia ou na Psicologia. $\mathrm{O}$ autor analisou ainda o que denominou de "a morte do homem" como evidência do esgotamento epistêmico dos saberes modernos em geral.

Em A Arqueologia do Saber (1969), Foucault discorre sobre a constituição dos saberes do ponto de vista da edificação dos seus discursos, seus conceitos, suas modalidades de formação e enunciação em suas dinâmicas de transformação.

Outra fase se sucedeu quando Foucault tematizou a inter-relação entre poder, saber e corpo na história do sujeito moderno. São desse período Vigiar e Punir (1975), em sua análise sobre a violência nas prisões e a gênese dos processos disciplinares modernos, e $A$ História da Sexualidade - volume I - A Vontade de Saber (1976), com seus estudos sobre a constituição histórica do dispositivo da sexualidade.

A constituição de um sujeito ético e de uma existência "bela e justa" foi estudada por Foucault sobre a Grécia e Roma Antigas em História da Sexualidade - Volumes II e III, sob o título $O$ Uso dos Prazeres e $O$ Cuidado de Si (1984).

Em um sentido amplo, Foucault estuda, através de uma arqueogenealogia dos saberes, "a história das relações que o pensamento mantém com a verdade"
(Escobar, 1984, p. 30), e desta maneira, como a correlação entre pensamento e verdade se estabelece na constituição de subjetividades locais, regionais e históricas, como se vê a seguir:

Através de quais jogos de verdade o homem se dá seu ser próprio a pensar quando se percebe como louco (A história da loucura), quando se olha como doente $(\mathrm{O}$ nascimento da clínica), quando reflete sobre si como ser vivo, ser falante e ser trabalhador (As Palavras e As Coisas), quando se julga e se pune enquanto criminoso (Vigiar e Punir)? Através de quais jogos de verdade o ser humano se reconheceu como homem de desejo (História da Sexualidade)? (Escobar, 1984, p. 75).

Sob um viés específico, podemos reconhecer que, para Foucault, os enunciados de verdades são raridades, na medida em que demandam um esforço de pensamento para que se alcance a sua expressão - a sua dizibilidade - a qual, freqüentemente, só é perceptível pelo pesquisador a partir de uma análise de amplos momentos históricos.

Por sua vez, vemos o estabelecimento de um jogo de pressuposição recíproca entre a raridade dos enunciados e a multiplicidade de sentidos deles advinda. Por exemplo, vemos pensar a reconhecível pluralidade de sentidos - compreendida enquanto "pletora do significado em relação a um significante único" (Foucault, 1969, p. 136) - que a enunciação de corpo possa vir a comportar - aliás, pluralidade evidenciada pelas variadas enunciações de verdades sobre o corpo estudadas por Foucault, por exemplo, corpos disciplinados, excluídos, delinqüentes, enlouquecidos, patologizados e outros.

Não obstante, a raridade da enunciação da palavra corpo, sobre a qual inúmeras formações discursivas se desenvolvem (por exemplo, a biologia, a psicologia, a medicina, a religião, a acupuntura, a astrologia), leva Foucault a estudá-la mediante amplas temporalidades, as quais não se relacionam diretamente com o suceder linear de eventos históricos, mas constantemente associadas a certos rearranjos de dizeres na produção de conhecimentos. Isto porque, para Foucault, episteme "não é uma forma de conhecimento, ou um tipo de racionalidade que, atravessando as ciências mais diversas, manifestaria a unidade soberana de um sujeito, de um espírito ou de uma época" mas, sim, "é o conjunto das relações que podem ser descobertas, para uma época dada, entre as ciências, quando estas são analisadas no nível das regularidades discursivas" (Foucault, 1969, p. 217). 
As emergências das raridades enunciativas no processo de formação de discursos e de conceitos foram analisadas na arqueologia de Foucault (principalmente em As Palavras e As Coisas, 1966, e em A Arqueologia do Saber, 1969) enquanto transformações epistêmicas, e como tais, sujeitas a um campo variado de relações, com suas rupturas e descontinuidades, nos processos de evolução histórica das mentalidades e dos saberes.

Este artigo focalizará a fase arqueológica foucaultiana, principalmente o livro As Palavras e as Coisas, analisando desta obra as formações discursivas do corpo (entrelaçadas às enunciações correlatas de vida e de homem) enquanto elemento fundamental no processo de subjetivação do homem moderno, com especial referência à constituição histórica do sujeito psicológico.

Aliás, é Foucault quem, em A Arqueologia do Saber, ao estudar as regras de formação dos objetos das formações discursivas, apresenta o conceito de grade de especificação como um dos norteadores de sua análise histórica dos discursos. Para tanto, parte do exemplo do desenvolvimento do discurso da psicopatologia. Nele reconhece suas diversas categorias, dentre elas as de doença, alienação, anomalia, demência, neurose ou psicose, degenerescência, etc., e a partir destas enunciações, indaga sobre qual foi o regime de existência da loucura enquanto objeto do discurso (Foucault, 1969, p. 47).

Neste contexto, denomina de grades de especificação aos

sistemas segundo os quais separamos,
opomos, associamos, reagrupamos,
classificamos, derivamos, umas das outras, as
diferentes 'loucuras' como objetos do
discurso psiquiátrico (essa grades de
diferenciação foram, no século XIX, a alma,
como grupo de faculdades hierarquizadas,
vizinhas e mais ou menos interpenetráveis; o
corpo, como volume tridimensional de
órgãos ligados por esquemas de dependência
e de comunicação; a vida e a história dos
indivíduos, como sequiência linear de fases,
emaranhado de traços, conjunto de
reativações virtuais, repetições cíclicas; os
jogos de correlações neuropsicológicas como
sistemas de projeções recíprocas e campo de
causalidade circular (Foucault, 1969, p. 48,
grifo nosso).

É sob esta ótica que os enunciados do homem, do corpo e da vida surgem feito grades de especificação, a partir das quais conceitos psicológicos (dentre eles os de psiqué, consciente, inconsciente, personalidade, comportamento, etc.) podem se interarticular na constituição da Psicologia enquanto campo de saber definido e diferenciado.

Através da leitura da bibliografia desse autor e de comentaristas, esta pesquisa estuda a questão do corpo na fase arqueológica foucaultiana, principalmente em As Palavras e As Coisas, destacando as formações discursivas do corpo, da vida e do homem em seus efeitos subjetivadores, com especial referência à constituição discursiva do sujeito psicológico.

\section{O ENUNCIADO DA CONSTITUIÇÃO DO SUJEITO MODERNO: A ENTRADA DO HOMEM NA HISTÓRIA}

Foucault aponta, em "As Palavras e As Coisas" (1966), ao estudar a arqueologia das ciências humanas, três grandes fases do pensamento ocidental: a Renascença (por volta do século XVI), a Época Clássica (séculos XVII e XVIII) e a Modernidade (séculos XIX e XX).

Até o fim do século XVI, a cosmologia da Renascença reconhecia semelhanças entre o homem e o macrocosmo, estabelecendo laços estreitos entre a natureza humana, os fenômenos na Natureza e a infinitude, de forma que "o mundo enrolava-se sobre si mesmo: a terra repetindo o céu, os rostos mirando-se nas estrelas e a erva envolvendo nas suas hastes os segredos que serviam ao homem" (Foucault, 1966, p. 33).

Construía-se o homem feito "espelho do mundo", a refletir os fenômenos da natureza e assemelhado aos reinos animal, mineral e vegetal, e ohomem siderado, tendo a natureza dos seus corpos/almas projetada a uma Grande Ordem Celestial, através de discursos que vasculhavam similitudes entre a natureza, o macrocosmo e o microcosmo individual:

[...] na vasta sintaxe do mundo, os diferentes seres se ajustam uns aos outros; a planta comunica com o animal, a terra com o mar, o homem com tudo que o cerca. A semelhança impõe vizinhanças que, por sua vez, asseguram semelhanças. O lugar e a similitude se imbricam: crescem limos nos dorsos das conchas, plantas nos galhos dos cervos, ervas no rosto dos homens; e o estranho zoófito justapõe misturando-as, as propriedades que o tornam semelhante tanto à planta como ao animal (Foucault, 1966, p. 34). 
Sobre o homem se desdobravam as estrelas, as constelações, os elementos da natureza e uma rede de forças telúricas e cósmicas que se remetiam entre si:

Existe, entretanto, nesse espaço sulcado em todas as direções, um ponto privilegiado (...): esse ponto é o homem; ele está em proporção com o céu, assim como com os animais e as plantas, assim como com a terra, os metais, as estalactites ou as tempestades. Erguido entre as faces do mundo, tem relação com o firmamento (seu rosto está para seu corpo como a face do céu está para o éter; seu pulso bate-lhe nas veias como os astros circulam segundo sua vias próprias; as sete aberturas formam no seu rosto o que são os sete planetas do céu); todas essas relações, porém, ele as desloca e as reencontramos, similares, na analogia do animal humano com a terra que habita: sua carne é uma gleba, seus ossos, rochedos, suas veias, grandes rios; sua bexiga é o mar e seus sete membros principais, os sete metais que se escondem no fundo das minas. O corpo do homem é sempre a metade possível de um atlas universal. (Foucault, 1966 - p. 38).

Ou, conforme as palavras de Paracelso, "o homem descobrirá que contém 'as estrelas no interior de si mesmo [...], e que assim carrega o firmamento com todas as influências"' (Paracelso, citado por Foucault, 1966 , p. 37), de tal forma que conceber o homem como foco de estudo separado do infinito simplesmente era inconcebível ou discursivamente impossível.

Com a Época Clássica, no transcurso dos séculos XVII e XVIII, houve uma desvalorização das similitudes da Renascença, revestindo-as de obscuridade enquanto um conhecimento vago, impreciso e, por isso mesmo, desqualificado. Repelida aos "confins do saber, [...] ela se liga à imaginação, às repetições incertas, às analogias nebulosas" (Foucault, 1966, p. 34). Para melhor analisar esta etapa, é preciso destacar a própria conceituação de episteme, elaborada por Foucault sobre a Época Clássica, enquanto

um sistema articulado de uma máthêsis, de uma taxinomia e de uma análise genética. As ciências trazem sempre consigo o projeto longínquo de uma exaustiva colocação em ordem: apontam sempre para a descoberta de elementos simples e de sua composição progressiva; e, no meio deles, elas formam quadro, exposição de conhecimentos, num sistema contemporâneo de si próprio. O centro do saber, nos séculos XVII e XVIII, é o quadro. Quanto aos grandes debates que ocuparam a opinião, alojam-se muito naturalmente nas dobras dessa organização (Foucault, 1966, p. 89).

Segundo Foucault, a Época Clássica é um período de ordenação dos diversos seres vivos da natureza com o intuito de estabelecer uma taxinomia da diversidade da vida no planeta, no processo de sistematização e de nomeação dos reinos animal, vegetal e mineral.

Ou seja, um deslocamento de uma ordem das razões cosmológicas para uma ordem do discurso enquanto representação "isto é, da linguagem, na medida em que ela representa - a linguagem que nomeia, que recorta, que combina, que articula e desarticula as coisas, tornando-as visíveis na transparência das palavras" (Foucault, 1966, p. 326327).

Assim a linguagem, na análise das coisas, tem uma função de decomposição destas em unidades simples para a facilitação das combinações dos seus respectivos elementos; e enquanto expressão do poder do discurso, "a linguagem transforma a seqüência das percepções em quadro e, em retorno, recorta o contínuo dos seres em caracteres. Lá onde há discurso, as representações se expõem e se articulam" (Foucault, 1966, p. 326-327). Assim, se ainda os elementos da natureza são considerados fruto da criação de Deus, o homem, de maneira até então inédita, torna-se $o$ ordenador do mundo criado.

Não obstante, o homem não era fonte transcendental de significação, porque o sentido já estava pronto enquanto imanência proveniente de Deus. Cabia ao homem, portanto, passar à ordem convencional da linguagem um sentido que já estava impregnado originariamente nas coisas. Em outros termos, o problema da correspondência entre as palavras e as coisas reduzia-se, no Classicismo, à tarefa de ordenar a grande criação celestial; e na medida em que o homem elabora o mapeamento dos reinos da natureza, ele se volta aos "temas vitalistas" como uma de suas frentes de trabalho, através da constituição de um saber em construção então denominado de história natural. Tais temas vitalistas sustentariam a nova articulação entre os enunciados do homem, da vida e do corpo.

Por outro lado, Foucault nega a existência das ciências da vida na Época Clássica (dentre elas, a Biologia), já que "até o fim do século XVIII, a vida não existe. Apenas existem seres vivos. Estes formam uma, ou antes, várias classes na série de todas as coisas do mundo" (Foucault, 1966, p. 75, grifo nosso). Assim, Foucault releva da enunciação da vida nesta fase o seu sentido meramente taxinômico na universal 
distribuição dos seres. Destarte, na Época Clássica a vida é apenas uma "categoria de classificação", e não "um limiar" enunciativo para a produção de novos saberes (Foucault, 1966, p. 75).

A própria díade corpo/alma ainda não se manifesta como fonte de estudos de cunho humanista, na medida em que "antes do fim do século XVIII, o homem não existia" enquanto um domínio próprio na produção do conhecimento, mas apenas enquanto "espécie" ou "gênero" catalogável pelas ciências naturais (Foucault, 1966, p. 324).

Mais especificadamente:

Os temas modernos de um indivíduo que vive, fala e trabalha segundo as leis de uma economia, de uma filologia e de uma biologia, mas que, por uma espécie de torção interna e de superposição, teria recebido, pelo jogo dessas próprias leis, o direito de conhecê-las e de colocá-las inteiramente à luz, todos esses temas, para nós familiares e ligados à existência das 'ciências humanas' são excluídos pelo pensamento clássico: não era possível naquele tempo que se erguesse, no limite do mundo, essa estrutura estranha de um ser cuja natureza (a que o determina, o detém e o atravessa desde o fundo dos tempos) consistisse em conhecer a natureza e, por conseguinte, a si mesmo como ser natural (Foucault, 1966, p. 327).

Sob tais campos discursivos, a importância da edificação de um "espaço taxinômico de visibilidade" poderia encontrar no corpo um suporte privilegiado para sua implementação; mas o caráter superficial da classificação dos seres levou à desqualificação dos corpos animais e da anatomia (em virtude da complexidade de tais corpos e de tais investigações) enquanto objetos de pesquisa, só voltando estes a ocupar um local de destaque científico no fim do século XVIII, através dos estudos de Cuvier (Foucault, 1966, p. 152).

Por outro lado, nos séculos XVI e XVII ocorreu a valorização das plantas, o que determinou o avanço dos estudos botânicos. Sobre tal assunto, Foucault (1966) considera que "a disposição fundamental do visível e do enunciável não passa mais pela espessura do corpo. Daí o primado epistemológico da botânica [...] na medida em que muitos órgãos constitutivos são visíveis na planta e não o são nos animais" (p. 151).

Quanto à postura do pesquisador no Classicismo, identifica-se uma dessensibilização sobre os corpos como fundamental para o esquadrinhamento dos reinos a serem elencados. Isto se deve à minimização dos apelos sensoriais do pesquisador ao efetuar suas pesquisas, através das seguintes "exclusões", já que revestidas de "incerteza", dificultando o estabelecimento de taxinomias universais: o ouvirdizer; mas também o gosto e o sabor, e uma limitação muito estreita do tato a designações de oposições bastante evidentes (como as do liso e do rugoso). Em decorrência, emerge o privilégio quase exclusivo da vista: "o sentido da evidência e da extensão" (Foucault, 1966, p. 146).

Estes posicionamentos do pesquisador sinalizam para uma verdadeira arqueologia das disposições sobre os corpos do homem enquanto estudioso e explicitam uma noção de campo corporal/sensório do sujeito pesquisador, de forma a ser possível reconhecer que esse campo, "muito mais do que o acolhimento enfim atento às próprias coisas, define a condição de possibilidade da história natural e do aparecimento de seus objetos filtrados: linhas, superfícies, formas, relevos" (Foucault, 1966, p. 147).

Em outras palavras, a disposição dos corpos/almas desenvolvida pelos intelectuais da Época Clássica propiciou a produção do conhecimento peculiar desse período, no qual os corpos estudados eram revestidos do caráter de uma mínima visibilidade, suficiente e restrita para os preenchimentos dos pressupostos a seguir:

[...] observar é, pois, contentar-se com ver. Ver sistematicamente pouca coisa [...] As representações visuais vão oferecer à história natural o que constitui seu objeto próprio [...] Esse objeto é a extensão de que são constituídos os seres da natureza - extensão que pode ser afetada por quatro variáveis. E somente por quatro variáveis: forma dos elementos, quantidade desses elementos, maneira como eles se distribuem no espaço uns em relação aos outros, grandeza relativa de cada um (Foucault, 1966, p. 148).

Ou seja, reafirma-se aqui o objetivo exclusivamente nomeador dos seres vivos desta fase histórica. $\mathrm{O}$ que se almejava era a definição e o acesso a certa economia de marcas corpóreas, de forma a permitir a mais eficaz e contínua nomenclatura e representação dos reinos naturais, tornando-os visíveis na sua multiplicidade difusa.

Se durante o Classicismo a natureza surgia como uma multiplicidade de reinos a serem esquadrinhados sem que, contudo, houvesse espaço para o homem como categoria distinta a ser discriminada no quadro clássico, o advento da Modernidade vem estabelecer novos horizontes de racionalidade, criando campos de produção e de dispersão de discursos ao redor da 
questão do homem e de sua natureza finita enquanto medida de todas as coisas.

Como conseqüência, esse reposicionamento discursivo do homem na História gerou uma nova formação dos demais seres vivos enquanto objetos do discurso, de forma que, "na representação, os seres agora não manifestam mais sua identidade, mas a relação exterior que estabelecem com o ser humano" (Foucault, 1966, p. 329). Ou seja, doravante o homem é o objeto central de um campo de verdades, passando a se destacar dos demais seres da natureza enquanto um domínio discursivo diferenciado e específico a ser estudado, servindo, assim, como grade de especificação a renovadas conformações de saberes em produção, devendo a ele se reportar todos os outros reinos da natureza.

Esta "métrica humanista" dos saberes emerge de maneira que "o homem aparece com sua posição ambígua de objeto para um saber e de sujeito que conhece" (Foucault, 1966, p. 328).

Dreyfus e Rabinow (1995) comentam tal questão a partir de que

[...] a atividade humana de construir o quadro não podia ser representada; havia, na hierarquia de Deus, um lugar superior para o sujeito de conhecimento, enquanto animal racional, mas não para aquele que representava, pois o homem,ser especial e diferente - aquele que ordena o sujeito -, não teria lugar no quadro que ele mesmo organizou [...] Na Época Clássica, não havia lugar para o homem que era, ao mesmo tempo, sujeito e objeto da ordenação. O homem não pode fazer parte do quadro clássico sem que todo um sistema se modifique radicalmente (p. 23).

Comparativamente às outras duas fases do pensamento ocidental aqui citadas, se na Renascença havia "uma metafísica da representação e do infinito" e no Classicismo "uma análise dos seres vivos", na Modernidade se constitui "uma analítica da finitude e da existência humana" (Foucault, 1966, p. 333).

Assim, no fim do século XVIII ocorre a entrada do homem na história". Trata-se da mutação de conformação discursiva denominada de analítica da finitude do homem: "é uma analítica [...] em que o ser do homem poderá fundar em sua positividade todas as formas que lhe indicam não ser infinito" (Dreyfus \& Rabinow, 1995, p. 22).

Esta nova conformação da episteme moderna foi acompanhada de uma revisão da articulação da concepção de vida e da sua funcionalidade enquanto objeto de análise de muitos saberes científicos.

\section{O ENUNCIADO DA ENTRADA DA VIDA NA HISTÓRIA}

Se nos séculos XVI e XVII ocorreu a valorização das plantas enquanto objeto de estudo, por ela se adequar aos pressupostos de superficialidade, continuidade e universalidade inerentes ao quadro clássico, os corpos animais e a anatomia só voltaram a ocupar um local de destaque científico no fim do século XVIII, através dos estudos de Cuvier e de suas pesquisas anatomofuncionais dos animais (Foucault, 1966, p. 152).

A reaquisição da importância dos estudos dos animais e da anatomia se deveu à introdução de um elemento temporal desqualificado nos estudos das plantas e destacado na natureza animal: a presença destacada da vida e da morte, mais visível nos corpos dos animais em geral. Esta ruptura do quadro clássico e o estabelecimento de um novo rearranjo dispositivo dos seres vivos ocorreram de maneira que eles passaram a ser reagrupados em torno do "enigma da vida" (Foucault, 1966, p. 320).

É possível esclarecer tal rearticulação discursiva na medida em que se relembram as características constitutivas da taxinomia clássica:

[...] Edificava-se esta inteiramente a partir das quatro variáveis de descrição (formas, número, disposição, grandeza) que eram percorridas, como num só movimento, pela linguagem e pelo olhar; e, nessa exposição do visível, a vida aparecia como o efeito de um recorte - simples fronteira classificatória (Foucault, 1966, p. 284).

\section{O ENUNCIADO DA ENTRADA DO CORPO NA HISTÓRIA}

Neste contexto de reformulações discursivas é que compreendemos que a entrada do homem na História só se tornou efetiva concomitantemente à produção dos múltiplos saberes científicos, típicos da Modernidade, os quais tiveram como ponto de apoio o corpo do homem moderno. Promoveu-se uma ampliação da espacialidade do corpo no universo dos discursos. O corpo se tornou um enunciado de indagações de várias ciências emergentes sobre o que viria a ser o homem, em seus mais diversos campos de estudo. Além desta ampliação da espacialidade discursiva do corpo, ocorreu uma centralização do corpo como foco dos estudos empíricos sobre a finitude do homem, "[...] marcada pela espacialidade 
do corpo, pela abertura do desejo e pelo tempo da linguagem" (Foucault, 1966, p. 331).

A partir da Modernidade, então, verifica-se uma proliferação de campos de verdades sobre o que é o corpo humano, o qual é enfocado sobre os mais diversos saberes emergentes: a medicina, a biologia, a antropologia, as ciências sociais, a economia, a demografia, a psiquiatria, o direito, a psicologia, a higiene, a política e outros.

Neste contexto, o corpo passa por dois deslocamentos transformadores de sua disposição no campo dos discursos. Por um lado, foi a partir da Modernidade que o corpo obteve um "status" de profundidade a ser discursivamente vasculhada, definida e explorada, de forma que a tridimensionalidade dos corpos passa a ser validada como contexto epistemicamente passível de se tornar objeto de pesquisa.

Se compararmos a Modernidade com os períodos anteriores da história dos enunciados do corpo, veremos que, na Renascença, o corpo se apresentava apenas como mera pontualidade residual, encravada na sua quase invisibilidade, na correlação das semelhanças articuladas entre o micro e o macrocosmo. No Classicismo, por outro lado, tem-se o corpo-superfície, sustentáculo de discursos que lhe imprimiam apenas certas sinalizações gerais - tais como ranhuras, linhas, fissuras inscritas na superfície dos corpos dos seres vivos em geral - no processo de representação e classificação dos seres vivos.

Assim, na Modernidade, o corpo se avoluma e contém dimensões espaciais a serem claramente discriminadas. Ele possui disposições funcionais (respiração, circulação, digestão, dentre outras), as quais passam a ocupar um lugar privilegiado nas pesquisas. Possui também uma série de sentidos e percepções que precisam ser enumerados e analisados, os quais provocam uma série distinta de estimulações a todos os sentidos do pesquisador. O corpo está sujeito aos processos desenvolvimentais (os quais, então, passarão a ser discriminados) advindos do passar do tempo e das transmutações e peculiaridades da cultura, da história e da sociedade. Ele passa a ser um corpo que, na somatória com outros corpos, produz a concretude fundamentadora da noção de população e de suas implicações demográficas, e se tornará a fonte intrigante de inúmeras pulsões e forças instintuais ancestrais. Ele se configurará como o ponto de apoio de diversos diagnósticos que elencarão uma série constantemente renovável de patologias e desvios comportamentais, e a imanência de vários padrões de normalidade.
Neste sentido, Foucault destaca a estreita relação entre a analítica da finitude do homem e o corpo como um de seus fundamentos centrais:

[...] Mas, à experiência do homem é dado um corpo que é seu corpo - fragmento de espaço ambíguo, cuja espacialidade própria e irredutível se articula contudo com o espaço das coisas[...] Isso quer dizer que cada uma dessas formas positivas, em que o homem pode aprender que é finito, só lhe é dada com base na sua própria finitude. Ora, esta não é a essência melhor purificada da positividade, mas aquilo a partir do que é possível que ela apareça. O modo de ser da vida e aquilo mesmo que faz com que a vida não exista sem me prescrever suas formas me são dados, fundamentalmente, por meu corpo [...] (Foucault, 1966, p. 331).

Destarte, tanto o homem como o corpo em suas finitudes são considerados invenções do pensamento moderno, em um jogo de práticas discursivas no qual as limitações do homem (suas positividades) são, ao mesmo tempo, "distintas daquelas condições que tornam o conhecimento possível (o fundamental) e equivalentes às mesmas" (Dreyfus \& Rabinow, 1995, p. 33). Assim, a partir do jogo de verdades, no qual o positivo e o fundamental se produzem e se interremetem, vemos Foucault apresentar as regras de transformação do homem e de seu corpo, produzidos no contexto da analítica da finitude:

[...] É nesse espaço estreito e imenso, aberto pela repetição do positivo no fundamental, que toda essa analítica da finitude - tão ligada ao destino do pensamento moderno vai desdobrar-se: é aí que se verá sucessivamente o transcendental repetir o empírico, o cogito repetir o impensado, o retorno da origem repetir seu recuo; é aí que se firmará, a partir dele próprio, um pensamento do Mesmo irredutível à filosofia clássica (Dreyfus \& Rabinow, 1995, p. 332, grifo nosso).

De acordo com os comentários de Dreyfus e Rabinow (1995, p. 34), os três duplos destacados por Foucault e acima expostos se referem, respectivamente, no processo de racionalização sobre o aparecimento do homem moderno, às seguintes questões:

a) "(1) como um fato, entre outros fatos, para ser estudado empiricamente e, além disso, como a condição transcendental de possibilidade de todo o conhecimento". 
A origem epistêmica desta problematização remonta à distinção kantiana entre empírico e transcendental. Segundo Rabinow e Dreyfus (1995), Kant tenta "resgatar a forma pura do saber da história e do mundo factual" (p. 35) a partir de um modelo de produção de conhecimento por ele sistematizado no qual os dados da realidade empírica, revestidos de obscuridade, poderiam ser depurados na dinâmica da produção de universais sobre o mundo e o homem, a partir desses mesmos elementos, fornecidos pela facticidade.

As limitações deste duplo empírico/transcendental, seja no que se refere à contaminação do transcendental, no processo de produção de saber, pela impossível separação do indivíduo cognoscente do mundo factual no qual está imerso, seja pelas próprias limitações dos enunciados científicos, ao não levarem em consideração os aspectos históricos que possibilitam a própria enunciação do saber científico e da constituição do seu respectivo campo de verdades, são focos de questionamentos que transpassam toda a arqueogenealogia de Foucault, conforme estamos apresentando, em parte, neste artigo.

b) "(2) [o aparecimento do homem] como cercado por aquilo que não pode se esclarecer (o impensado) e, além disso, como um 'cogito' potencialmente lúcido, fonte de toda a inteligibilidade".

A Modernidade, ao pressupor o homem e seu corpo como focos privilegiados de produção do conhecimento enquanto objetos nos jogos confusos do duplo empírico/transcendental, torna-os elementos em uma concepção discursiva que investe a humanidade/corporeidade modernas enquanto lugares do desconhecimento.

É neste sentido que Foucault observa que as verdades ocultas a serem desveladas sobre uma sondável natureza humana só podem emergir em uma articulação discursiva "segundo a qual o pensamento se dirige ao impensado e com ele se articula" (Foucault, 1966, p. 341).

No que principalmente nos interessa do duplo pensado/impensado, Foucault reconhece que, na medida em que é

dado a um pensamento objetivo percorrer o homem por inteiro - com o risco de nele descobrir o que precisamente jamais podia ser dado à sua reflexão nem mesmo à sua consciência: mecanismos obscuros, determinações sem figura, toda uma paisagem de sombra a que, direta ou indiretamente, se chamou inconsciente. [...]
De fato, o inconsciente e, de maneira geral, as formas do impensado, não foram a recompensa oferecida a um saber positivo do homem. O homem e o impensado são, ao nível arqueológico, contemporâneos (Foucault, 1966, p. 342, grifo nosso).

Em outras palavras, Foucault questiona a própria existência natural ou essencial de uma instância psíquica denominada inconsciente, mas a situa em uma série de acontecimentos discursivos que permitem a emersão destes discursos "psi" em questão. Ou seja, se podemos conceber o inconsciente, isto se dá a partir de uma abordagem arqueológicodiscursiva que questiona, inclusive, sua anterioridade a determinada ordem discursiva, a qual produziria a própria possibilidade de pensá-lo.

Assim, depreende-se que o inconsciente não é uma descoberta empírica (positiva), mas constitutiva da Modernidade, porque representa o inapreensível do homem (o impensado, o cogito vazio, etc.), fazendo parte do contexto da formação discursiva da finitude do homem.

c) (3) [o aparecimento do homem] como o produto de uma longa história cujo início nunca poderá alcançar e, além disso, paradoxalmente, como a fonte desta mesma história".

Foucault questiona a pretensão do homem de encontrar a sua origem perdida no mundo e no tempo, então considerada, principalmente pelos historiadores do século XIX, como longínqua e de difícil acesso. É justamente este fundamento de difícil acessibilidade que Foucault irá implodir. Isto porque considera que

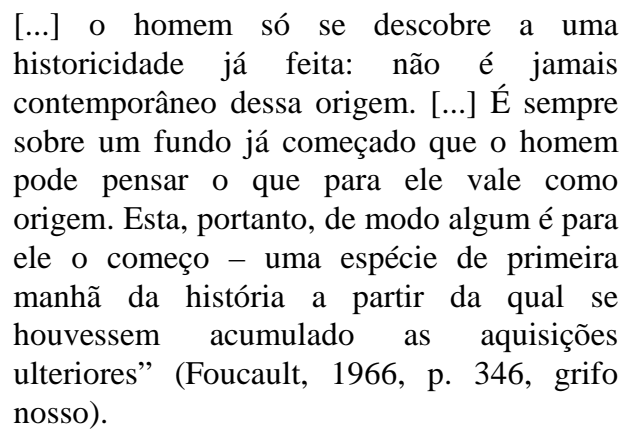

E acrescenta: “(...) a origem é, bem antes, a maneira como o homem em geral, como todo e qualquer homem, se articula com o já começado do trabalho, da vida e da linguagem" (Foucault, 1966, p. 346, grifo nosso). Ou seja, é dentro de determinado campo de verdades, historicamente situadas, que a noção de origem pode ser produzida.

O recuo do homem da origem, destacado por Foucault, é a regra de determinada conformação 
discursiva moderna que funciona, semelhantemente ao pensado e o impensado do homem, enquanto concepções discursivas arqueologicamente coincidentes, mas sob outro mecanismo dispositivo.

A relação recuada do homem com sua origem pressupõe que os discursos da origem do homem se situam em uma temporalidade distante e primitiva, se referida ao homem concebido na modernidade, o qual usaria dos saberes contemporâneos para desvendar os mistérios de sua origem selvagem.

Este tipo de pressuposição cria uma verticalidade temporal do homem no processo de conhecimento de sua origem. Desta maneira, falseia e oculta o fato de que ambas as concepções são, na verdade, como já dissemos, arqueologicamente coincidentes.

Este aspecto se aplica também aos discursos que buscam a origem fundante dos fenômenos corpóreos, sejam eles do ponto de vista da biologia, da medicina, da genética, da psicanálise, da psicologia ou de outros saberes humanistas.

Desse modo a realidade do corpo é imanente aos embates histórico-discursivos dos duplos estudados, nos múltiplos enredamentos enunciativos sobre a finitude do homem, modernamente considerado.

\section{DISCUSSÃO}

O objetivo deste mapeamento arqueológico das disposições do corpo, da vida e do homem visa compreender o fenômeno corpóreo do ponto de vista enunciativo, que se refere à sua disposição num jogo de discursos com o intuito de edificar a arqueologia da sua ocorrência, importância, movimentação e evolução, a qual pode se projetar em macromomentos históricos.

É o que nos permite compreender a psiqué também enquanto grade de especificação e de produção de discursos, como os enunciados do corpo, da vida e do homem. Ou seja, permite-nos compreende a psiqué não como emanação ou essência metafísica do corpo, mas como instrumento construído historicamente, com intuito diagnóstico - constitutivo de um saber - e de intervenção estratégica - enquanto exercício de poder, temática que será melhor aprofundada por Foucault em estudos posteriores, da sua fase genealógica ${ }^{2}$

Não há interioridade a ser desvelada, apenas a necessidade fundamental de visualizar os deslocamentos dos corpos e almas nas práticas discursivas, as quais permitem não só a dizibilidade,

\footnotetext{
2 Sobre esta temática, consultar Silveira e Furlan (2003).
}

mas a própria visibilidade do sujeito estudado, principalmente no que se refere ao nosso campo de estudo, que é a Psicologia e seu respectivo sujeito psicológico. Sobretudo, o enfoque foucaultiano não tem caráter ontológico de descoberta da "natureza", do que venha a ser o corpo e a alma, ou seu caráter "essencial"; mas é um instrumental para a análise das forças presentes em um campo de batalha discursivo, e não só discursivo, mas também material, na constituição e sucessão do corpo e da alma na história.

Dessa forma destacamos a aplicabilidade transdisciplinar da analítica corpóreo-anímica de Foucault, em especial no contexto específico da Psicologia, no sentido de sensibilizar seus estudiosos sobre a constituição sócio-histórica de uma série de conceitos psicológicos que são anexados "animicamente" aos corpos dos indivíduos.

Acreditamos que, a partir da concepção de corpo atravessada de história, cartografada arqueologicamente, seja possível instrumentalizar a Psicologia com uma analítica sobre os mecanismos de produção de verdades sobre os indivíduos, mecanismos que a atravessam enquanto ciência humana. Destarte, contribuindo para dar melhor relevância ao corpo historicamente constituído, certamente a arqueologia de Foucault nos previne contra tendências psicologizantes que ignoram os mecanismos enunciativos de produção de verdades sobre o homem na História, e pode servir de orientação sobre o relevo (prático-discursivoepistemológico) no qual a Psicologia emerge constante e movediçamente, já que ela é um saber que dispõe de um acesso privilegiado aos corpos através da "alma", em constante embate e produção de significações, sentidos e subjetivações.

\section{REFERÊNCIAS}

Dreyfus, H., \& Rabinow, P. (1995). Michel Foucault: uma trajetória filosófica (V. P. Carrero, Trad.). Rio de Janeiro: Forense Universitária.

Escobar, C. H. (Org). (1984). O Dossier: últimas entrevistas. Rio de Janeiro: Livraria Taurus.

Foucault, M. (1961). A História da loucura na idade clássica (5ª ed.). São Paulo: Perspectiva.

Foucault, M. (1963). O nascimento da clínica ( $2^{\mathrm{a}}$ ed.). Rio de Janeiro: Forense-Universitária.

Foucault, M. (1966). As palavras e as coisas: uma arqueologia das Ciências Humanas. São Paulo: Martins Fontes.

Foucault, M. (1969). A arqueologia do saber. Rio de Janeiro: Forense Universitária.

Foucault, M. (1975). Vigiar e punir: nascimento da prisão (14 $\left.{ }^{\mathrm{a}} \mathrm{ed}.\right)$. Petrópolis: Vozes. 
Foucault, M. (1976). História da sexualidade I: a vontade de saber (11 ${ }^{\mathrm{a}}$ ed.). Rio de Janeiro: Graal.

Foucault, M. (1984a). História da Sexualidade II: o uso dos prazeres ( $7^{\mathrm{a}} \mathrm{ed}$.). Rio de Janeiro: Graal.

Foucault, M. (1984b). História da Sexualidade III: o cuidado de si ( $5^{\mathrm{a}}$ ed.). Rio de Janeiro: Graal.
Silveira, F. A., \& Furlan, R. (2003). Corpo e Alma em Foucault Postulados para uma Metodologia da Psicologia. Revista Psicologia USP, 14(3), 171-194.

Recebido em 8/12/2006

Aceito em 15/01/2007

Endereço para correspondência : Fernando de Almeida Silveira. Avenida Saldanha da Gama, 89, CEP 11030-400, Santos -SP. E-mail: fernando.silveira@unifesp.br 